\title{
Transnational Digital Intimacy Practices: Paradoxes of Transnational Connectivity and Home-Making among Young Adult Expatriates in Amsterdam, the Netherlands
}

\author{
Jeffrey Patterson ${ }^{1}$, Koen Leurs ${ }^{2}$ \\ ${ }^{1}$ Netherlands Research School of Gender Studies, Utrecht University, the Netherlands, jeffpatterson04@icloud.com, 2 Graduate Gender Programme, \\ Department of Media and Culture, Utrecht University, the Netherlands \\ Keywords: home, co-presence, mobile subjects, expatriates, transnational connectivity, digital intimacies \\ https://doi.org/10.1525/gp.2020.13346
}

\section{Global Perspectives}

Vol. 1, Issue 1, 2020

\begin{abstract}
Personal and intimate consequences of cultural globalization have received little critical attention in comparison to scholarship on politics, finance, or the environment. Taking digital technology practices of young adult expatriates as an entry point to understand the emotional and affective consequences of transnational mobility, in this article we research the interrelated cultural politics of emotion, migration, and digitization of middle-class mobilities. Presenting a case study of digital experiences of young adult expatriates (aged fifteen to twenty-five years) living in the Netherlands, we seek to better understand how emotions and affects of middle-class transnational mobility are mediated through digital technologies. Our empirical argument draws from thirty-one semistructured, face-to-face in-depth interviews with young adult expatriates and smartphone photo-elicitation exercises. We develop the notion of transnational digital intimacy practices to address how transnational mobile subjects negotiate emotional precarity through selective smartphone and social media practices. Finally, we call into question the notion of "expatriates" as supposed elite mobiles with global privilege. This article is part of the Global Perspectives, Media and Communication special issue on "Media, Migration, and Nationalism," guest-edited by Koen Leurs and Tomohisa Hirata.
\end{abstract}

\section{INTRODUCTION}

Media and migration scholars have recently called for attention to the personal, intimate, and emotional consequences of mobilities beyond rational decision-making processes as they have received little scholarly attention (e.g. Alinejad 2019; Awad and Tossell 2019; Cabalquinto 2018). Taking digital technology practices of young adult expatriates as an entry point to understand the emotional and affective consequences of transnational mobility, in this article we research the interrelated cultural politics of emotion, migration, and digitization of middle-class mobilities. We bring into conversation media (e.g. Diminescu 2020) and feminist theory (e.g. Ahmed 2004) with migration and mobility studies (e.g. Elliot and Urry 2010). "Expatriate" here refers to middle-class individuals of industrialized countries who are increasingly expected and/or encouraged to relocate internationally in pursuit of career-related or higher education opportunities. They move temporarily or permanently to a country of which they are not a citizen as a consequence of cultural and economic globalization (Beck and Beck-Gernsheim 2015; Valentine 2008). Expatriates use digital technologies, such as the smartphone and social media, to maintain digital co-presence with their key transnational connections (i.e., family, friends, and romantic partners) residing in their country of origin and to connect with members of the host country (Diminescu 2020). As the number of expatriates is projected to exceed seventy million by 2021, or one-third of the world's migrant population (FinAccord 2018, 1-3), understanding the emotional and affective consequences of cultural globalization, hightech capitalism, and the internationalizing of education is urgent.

Expatriates are generally thought of as "privileged" mobile subjects, having access to forms of economic, symbolic, and social capital that allow them to benefit from internationalization (Rodriguez and Ridgway 2018). However, the supposed elite status and privilege of expatriates demands critical scrutiny, as they render invisible the emotional and embodied consequences of middle-class transnational mobility. Erika Polson (2016) addresses expatriates from the perspective of class performativity, which is useful to the understanding of how middle-class mobile subjects dynamically establish their position "as a set of cultural practices," a continuous process of reenactments and recreations. Rather than distinctly framing class as a socioeconomic category, cultural "distinctions" between the upper, middle, and lower classes are actively constructed (Bourdieu 1984). The middle class strategically creates and leverages both "cultural capital" and "social capital" as means to improve their positions in the social world to accumulate or compensate for the lack of economic capital (e.g. Polson 2016, 9). More specifically, with the proliferation of communication technologies, mobile subjects are expected to cope with their global lifestyles through "intimacy-at-a-distance," but Anthony Elliott and John Urry wonder to what 
extent these practices hollow out emotional bonds:

There is a kind of in-built tension or contradiction between the global mobile economy, which privileges speed of movement and fast rational calculations, on the one hand, and the sociocultural order of intimacy in which personal and familial relationships become increasingly ordered around short-termism, episodicity and communications at-a-distance, on the other. (2010, 110)

The systemic conditions expatriates face remain relatively invisible because the recent growth of international expatriate mobility parallels increasing neoliberal, individualized forms of self-development and self-care. In the contemporary moment, internationally mobile subjects like expats are expected to embody the rational, ideal-type "entrepreneurial self” (Heidkamp and Kergel 2017, 99). As this has commonly been the central focus, the experiences and sensations of "emotional precarity" are commonly glossed over (ibid 102). For expatriates, emotional precarity may result from a combination of physical distancing from friends, family, and other significant others, irregular contracts, insecure visa status, and constant demands of flexibility.

Scholarship on expatriate youth commonly celebrates younger expatriates as "third-culture kids" who develop an "expanded worldview" (Pollock and Reken 2009, 107-18). Due to the dominant discourses of this particular group's "privilege," its members are oftentimes expected to develop an elite "belonging" to a global cosmopolitanism irrespective of their local settings and communities (Calhoun 2003; Nessi and Bailey 2014), and they are thought to be at ease with a mobile and cosmopolitan lifestyle. However, young adult expatriates generally grapple with cultural expectations, values, beliefs, and language demands that often differ from their country of origin. Due to their perceived differences from members of the host country, they might encounter stereotyping, exclusion, racism, and discrimination (Hofhuis, Hanke, and Rutten 2019).

In this article, we propose the notion of transnational digital intimacy practice to account for the strategic selectivity of smartphone use and social media as care practices performed by young adult expatriates (aged fifteen to twenty-five years) living in the Netherlands, in the face of emotional precarity. This approach will yield a better understanding of how emotions and affects of middle-class transnational mobility are mediated through digital technologies. Our empirical argument draws from thirty-one semistructured, face-to-face in-depth interviews with young adult expatriates. The interviews included a photo elicitation exercise wherein participants were invited to self-select photos from their personal smartphone pocket archive to reflect upon their emotional migration trajectories. Following a non-digital-media-centric approach, we aim to become attentive to the relationalities between the on- and offline experiences of young adult expatriates. Before we discuss the main findings, we first provide an overview of literature on intimacies in relation to migration and digital media. Second, we reflect on our methodological approach, assumptions, positionalities, and ethical commitments. Third, we bring to the fore our empirical findings in two sections as follows: the paradoxes of (1) polymedia affordances and transnational familial longing; and (2) home-making, homesickness, and senses of belonging.

\section{CONCEPTUALIZING TRANSNATIONAL DIGITAL INTIMACY PRACTICES}

Intimacies are exchanges, relations, activities, and situations between bodies regardless of their processes of mediation. Moving beyond the dominant notion of intimacy as a relation practiced by heteronormative models of the "Western couple," we refer here to intimacy as the deep connections established and sustained between people regardless of sociocultural categories like age, race, nationality, gender, and sexuality. We follow Helga Sadowski (2016) in recognizing intimacy as "a context that is relational, and that this relation affects one's body and embodied self. In this broad definition, intimacy thus becomes a close, affective relation" (46-47). Intimacy can include affective relations between family, friends, peers, and romantic partners, some of whom may live in close proximity and others who may reside abroad elsewhere; therefore, they often resort to digital technologies to keep connected.

Intimacies reconfigure affects and emotions. Following the Spinozan-Deleuzian train of thought, affect refers to the body's nonconscious ability to be and to act, to refuse and to invite (Gregg and Seigworth 2009), to experience intensity in an unstructured and unformed dimension (Wise and Velayutham 2017). Here, we distinguish between emotion and affect as follows: while affect can be taken to understand the unpredictable intensities and transitions in bodies in response to certain objects, people, or events (bodies have capacities for affecting and being affected); by emotion, we mean how we consciously move away or toward objects, people, and happenings (Ahmed 2004). Affects thus are pre-emotional, while emotions are biographically registered affects (Massumi 2015, 3). Transposed to the digital domain, feminist media scholars Kaisu Hynnä and colleagues address the distinctive affective body politics, recognizing that "on social media, the oscillating registers and dynamics of affect shape online connections and disconnections between bodies, giving rise to new assemblages" $(2019,2)$. It is not somehow the rational end result of being emotional, or having affective responses, that we consider important but the very process itself, what Sara Ahmed describes as the "processes of production or the 'making' of emotions” (2004, 11).

Besides affective and emotive, further specifications indicate that intimacies are distinctive and thus can be expected to diverge across spatiotemporal contexts and situations and among people. To account for this ambiguity and dynamism, we build here on sociologist Lynn Jamieson's (2011) definition of intimacy as "the quality of close connection between people and the process of building this quality" (1), which includes knowing, loving, and caring for someone. More specifically, we take up her suggestion to focus on "practices of intimacy" to become attentive "to practices which enable, generate and sustain a subjective sense of closeness and being attuned and special to each other" (Jamieson 2011, 1). In a similar vein, we also draw upon Monique Scheer's (2012) concept of "emotional practices" as a lens through which we conceptualize intimacy as "habits, rituals and everyday pastimes that aid us in achieving a certain emotional state" (209). Transnational digital intimacies refer to the performing of ritualistic affective and emotional interpersonal connection and disconnection practices across borders through specific use of digital technologies.

In critical sociology and cultural geography, intimacy is thought of as a practice of “doing," through active care 
work and relationship maintenance among family members. From initial restrictive understandings of intimacy as pertaining to families of birth or choice, the focus has shifted gradually into studying intimacy as an active doing across a "range of personal relationships (i.e. non-co-residential partnerships, friendships, communities) that provide intimacy, care and companionship" (Valentine 2008, 2105). Across these fields, scholars raise questions about the various changing forms of reciprocal support and care in intimacies across relationships, as well as point out how cultural geographies are reshaping power relations within intimate relationships.

For example, Tracey Reynolds and Elisabetta Zontini (2013) highlight how migrants who sustain intimacy through doing family across borders are seen as nonnormative. Migrant intimacies, in the form of doing family life across borders, disrupt "bonds of place, country and family" (Beck and Beck-Gernsheim 2015, 13). By turning to feminist theorizing on the performativity of normative roles, we can further understand how intimacies at distance might implicate emotional precarity as some practices are normalized and expected and others are seen as transgressive. Ruth Preser (2018), for example, notes that "intimacy is understood, performed and experienced against the backdrop and in response to prevailing discourses of tolerance which regulate the public sphere" (1). Intimacy, as an active doing, can thus be understood as a performative practice revolving around a set of normative expectations.

Intimacies are, however, fluid, in constant negotiation, and can transgress cultural, national, and (hetero)normative expectations. In the words of Lauren Berlant (2011), "the kinds of connections that impact on people, and on which they depend for living (if not 'a life'), do not always respect the predictable forms," raising the question "What if we saw it emerge from much more mobile processes of attachment?" (284). Intimacy, as a performative practice that affects the bodies involved, revolves around the active maintenance of deep connections-for example, through repetitive and ritualized forms of interpersonal communication. These may be rational and calculated, as well as unpredictable, paradoxical, and haphazard. Intimacies are, furthermore, taking place not in a void but in a power-ridden situated context that reflects and possibly also challenges norms and expectations. This perspective on performative intimacy practices, we feel, aligns well with the fluidity and complexity of affective experiences, especially in the context of transnational mobile populations. While it is true that cultural practices are also in the making as migrants engage in multiple cultural affiliations, previous cultural and social experiences and understandings might still shape the way people emotionally engage with (and are expected to engage with) situations/relations in their new surroundings. Due to the consequences of cultural globalization, high-tech capitalism, and the internationalizing of education, intimacy practices are becoming increasingly digitally mediated.

\section{DIGITAL INTIMACIES IN POLYMEDIA ENVIRONMENTS}

The body, the domestic home, and the neighborhood have been principal sites for studying intimacies (Walsh 2018). It is only in recent years that digital intimacies have attracted scholarly attention. Initial studies emphasized the ambiguous consequences of digitization for intimacy practices: "ICT [Information and Communication Technologies] do not necessarily impact on 'the doing of intimacy' in fixed ways, either positive or negatively” (Valentine 2006, 389).
Recent studies have suggested various approaches to further unpack these uncertainties. Digital intimacies, for the most part, cover the "public" display of intimacy on social media platforms (see Dobson, Robards, and Carah 2018; Miguel 2016). However, Elisabetta Costa and Laura Menin rightly question the dominant attention for digital media in relation to public contexts, political transformation, and activism, which overlook personal and private micropolitical implications of digital mediation $(2016,137)$. They argue that "digital intimacies" can be taken up to "indicate the spheres of personal relationships, affects and sexuality mediated by new digital communication channels" (ibid). Thus, we need to consider digital intimacies differently:

It is about moving along with affective flows, paying close attention to the co-shaping of novel technologies with oneself, the body, and subject positions, and critically interrogating the assumptions and norms on which many of the contemporary engagements with the digital are built. (Sadowski 2016, 195)

Digital intimacy results from a specific sociotechnological arrangement: situated user bodies are able to affect and be affected by mediating their emotions through their personal appropriation and tinkering with medium-specific affordances of smartphones and polymedia environments. Polymedia allow an "always-on lifestyle"; for Mirca Madianou, "navigating this [polymedia] environment becomes particularly meaningful in mediated personal communication as users exploit differences between media to express emotions and manage mediated relationships" (Madianou 2014, 678).

Medium-specific affordances refer to how properties of individual apps, platforms, and technologies are taken up according to specific interests, and cultural contexts, particular to time and space. Polymedia refers not to specific essences of particular channels or media but to how, in their usage, they are relationally defined vis-à-vis each other. Typed, aural, visual, and haptic modes of communication, or a combination thereof, allow a sense of privacy or publicity, synchronicity and/or simultaneity, asynchronicity, and scalability, targeting specific micro audiences, such as peer groups, local contacts, and transnational connections (boyd 2014). For example, Maryam Abolfazli describes how the technological feature of knowing in a messaging app when someone is writing a response after sending a message is imbued with personal meaning making and affective intensities of connection and disconnection: "The three dots shown while someone is drafting a message in iMessage are quite possibly the most important source of eternal hope and ultimate let down in our daily lives" (cited in Sundén 2018, 74). Access to and usability of media are important conditions to first recognize. If both conditions are met, then the choice between certain platforms or mediums through which to communicate feelings, emotions, and everyday lived experiences of transnational mobility becomes a careful practice (Alinejad 2019) and an emotional experience. The various emotional and affective intensities of mediated intimacies are in relation to the deliberate and careful practices of social media affordances.

\section{MIGRANT AND TRANSNATIONAL DIGITAL INTIMACIES}

Through the notion of transnational digital intimacy practices, we build on the realization that mobile subjects tactically and playfully navigate media environments, including the smartphone and social media platforms, but seek to further tease out the often paradoxical emotional intensi- 
ties of maintaining deep transnational connections. Mobile subjects, in lieu of physical proximity, maintain mobile relationships through acts of "intimacy-at-a-distance" (Elliot and Urry 2010, 850). Families with members living across geographical borders engage in "cross-border communication" practices that reveal an invention of "own procedures and practices through a process of reflexive negotiation" about misunderstandings, silences, and disputes (Beck and Beck-Gernsheim 2015, 171).

Digital migration scholarship has elaborated on the ways in which migrants strategically navigate social media apps and platforms to keep in touch with family and friends from a distance. They are expected to navigate the "pains and gains" of performing digital intimacies, argues Earvin Charles Cabalquinto in his work on overseas Filipino workers living in Melbourne, Australia (2018, 248). His informants deployed various "strategies of control" through Facebook's affordances in their maintenance of transnational digital intimacies (2018, 247-48), which are reflective of gendered, classed, and nation-based power relations. The performativity of intimacy practices shows how Filipinos abroad negotiate the emotional consequences of mobility. He argues that "behind every customised post lies the tears, strain, and constant struggles of separated family members to perform and reclaim a satisfying and intimate relationship beyond borders" (2018, 260). Mirjam Twigt (2018) has accounted for the specific "affective affordances" of smartphones and social media, shedding light on how Iraqi households living in Jordan navigate "the potential of different media forms to bring about affects like hope and anxiety" (p. 1). Research on mediated child-rearing practices show new ways in which media practices expect migrants "to balance distance and intimacy in communication” (McKay 2018, 137). Our case study aims to further deepen emerging discussions on the mediation of intimacy by focusing on how particular class-based differentiated mobile subjects' practices and experiences of affecting and being affected converges or diverges with other mobile groups.

Through case studies, scholars have begun to document how this careful balancing is done in practice. In his study with young Punjabi migrants in Manila, the Philippines, Jason Vincent A. Cabañes (2019) found that they mobilize digital practices as a "temporary resolution," using specific apps for specific audiences to negotiate their "double consciousness of intimacies" across diaspora and local communities (1662). With the notion of "transconnective habitus," Sara Marino (2019), in her work with Italians in London, addresses how the activities of food preparation, cooking, and dining, mediated through the video-sharing platform Skype, construct a sense of "emotional proximity" but also "exacerbate feelings of nostalgia and migrants' sense of deterritorialization” $(788,799)$. In her work with second-generation Turkish-Dutch migrants, Donya Alinejad found that in their maintenance of transnational emotional family intimacies, they shift between ambient and direct modes of communication, a process she calls "careful co-presence" $(2019,1)$. Based on fieldwork with young refugees in the Netherlands, Koen Leurs (2019) found that their perceived sense of obligation toward "maintaining bonds" with family members abroad and "keeping face" resulted in positive but also "negative affective intensities such as fear, anxiety, shame and guilt" (641). Thus, we see how the strategic selection of "aural, visual, and haptic affordances" (ibid) is often a constant negotiation while performing digital intimacies. Finally, Isabel Awad and Jonathan Tossell note that, in particular, the "emotional precarity" of mobile subjects re- mains understudied (2019, 3). Importantly, they also caution against taking a "utilitarian" approach to migrant connectivity (Awad and Tossell 2019, 1). In searching for how digital practices might offer solutions to challenges faced by migrants (such as a lack of information), scholars risk overlooking the striking similarities between migrants' use of the media and other populations' user practices. By focusing, in particular, on young expatriates in the Netherlands, we seek to (1) zoom in on the broader spectrum of the ambiguous emotional and affective consequences of middleclass transnational mobility, and (2) build on the emerging discussion of transnational intimacy by accounting for how mobile subjects negotiate expectations of intimacy and emotional care all while staying attentive to their on- and offline daily lives.

\section{RESEARCH CONTEXT: GLOBAL NETHERLANDS}

The Netherlands is an attractive country for expatriates due to its increasingly high number of internationally oriented companies and its competitive higher education opportunities. It is estimated that 57,000 expatriates and 48,000 international students live in the Netherlands, and these figures are predicted to rise (CBS 2018; Hofhuis, Hanke, and Rutten 2019). It is estimated that Amsterdam-considered to be a super diverse city (Crul 2016)-is the city with the largest number of international degree students in the country, totaling 12,858 (The Dutch Organization for Internationalisation of Education 2019). The country also attracts international companies; due to Brexit, the United Kingdom's decision to withdraw from the European Union, around 397 international companies chose to relocate their offices in the Randstad region, a megalopolis in the central-western Netherlands consisting mainly of the four largest populated cities: Amsterdam, Utrecht, Rotterdam, and The Hague. According to Employment Conditions Abroad Limited (ECA), the majority of cities in the Randstad region are among the top twenty most livable locations for European expatriates (Employment Conditions Abroad Limited (ECA) 2019). Furthermore, an estimated 14,000 job opportunities are to be created within the next three years (Invest in Holland 2020).

The Dutch national identity rests upon a collective notion of tolerance, openness, and belonging (Wekker 2016). Amsterdam "is known for its discourse of inclusion and city policies that often resemble a pro-diversity attitude" (Belabas, Eshuis, and Scholten 2020, 11). Amsterdam is frequently described using terms such as "cosmopolitan," "world-orientated," "openness," and "diversity," which hold particular appeal for expatriates: "its diverse population exudes an open ambience that encourages encounters and exchanges between people, while also providing residents with useful skills such as multilingualism" (Belabas, Eshuis, and Scholten 2020, 11). For example, Mike, a twenty-twoyear-old informant from Italy, shares that "maybe this is the place for me to reach the one hundred percent," "[a place where] I can actually explore my sexuality more. I can explore the person that I am more and get to know myself even better than I thought I knew myself before." Acknowledging that intersectional identities of young mobile subjects at the crossroads of coming of age and migration are dynamic and evolving, we can understand Mike's strategic choice to move to Amsterdam from a small Italian city. The city in which Mike was raised is quite conservative, a place where homosexuality is not necessarily accepted; he felt he could not always be his true, authentic self. By acknowledging both Mike's "previous” identity positioning (i.e., feelings of not being able to be his "true" self) and the "new- 
er-ing identity" as an expat living in Amsterdam (in tandem with the old and continuously becoming) (Yu 2019), we can begin to see how Amsterdam can be a place of new identity making for some individuals. However, the Netherlands' "traditions of tolerance" should be met with skepticism of its color blindness and denials of racism (Wekker 2016), which we will also demonstrate in our empirical section drawing from the experiences of our study's informants. What we aim to highlight is that with the growing number of expatriates residing in the Netherlands, it is important to investigate, reflect upon, and challenge the dominant discourses of young adult expatriates being at ease with a mobile and cosmopolitan lifestyle in a supposedly "open and tolerant" country.

\section{METHODOLOGICAL CONSIDERATIONS}

In this study, we aim to capture and understand young adult expatriates' complex practices and experiences of mediating affect and emotion across distance. To help achieve our aim, we built this study upon the principles of feminist grounded theory. Seeking to offer a more holistic account, we draw on grounded theory "to develop theories from research grounded in data rather than to test existing theory by deducing testable hypotheses from them" (van Meeteren $2014,45)$. In particular, by taking a feminist approach to grounded theory, we approach informants as the meaning makers in their own lives, with particular attention to their experiences of agency, emotionality, and power structures. We also draw upon a non-digital-media-centric approach, which cautions us about technological fetishism, placing digital media at the epicenter while overlooking the onand offline entanglements of the informants' worlds. This ethnographic approach conceptualizes digital media as a form of mediation of everyday life (Candidatu, Leurs, and Ponzanesi 2019) and seeks to highlight the intersecting factors of inequalities including age, race, nationality, migration status, gender, and sexuality across spaces, moving beyond the notion of a "fixed" or "static" locality (Tsagarousianou 2020).

We sought to establish a space for collaboration between the informants and us researchers during fieldwork. As part of the interviews, we drew on photo elicitation to invite informants to share and narrate their personal experiences of practicing digital intimacy. In our attempt to produce knowledge with study informants in a transformativeemancipatory way, participants were invited to self-select and reflect upon material from their pocket archive-most notably photographs - to facilitate a "deeper reflection on the often taken-for-granted and previously unexplored aspects of life [bringing] a richness and depth to data generated in interviews" (Kaufmann 2020, 172). Photo elicitation is a compelling tool for media and migration scholars to understand the nuanced proximity and reliance (Kaufmann 2020) on the smartphone by migrants in relation to the emotional and affective consequences of transnational mobility.

The semistructured interviews were based on a topic list, which was structured into four sections: (1) ethnocultural roots and the concept of "home"; (2) discussing personal family and friend (trans)national relationships, routines, and rituals; (3) exploring the uses of social media platforms and polymedia environments; and (4) inquiring into the overall offline experiences of residing in urban cities in the Netherlands. The various social media platforms and polymedia affordances discussed in the empirical section reflect the most prominently discussed platforms and environ- ments by our study's informants. In line with our non-digital-media-centric approach, we did not single out particular social media platforms a priori.

As a self-identifying expatriate from Canada, the first author felt comfortable among the demographic that he was researching. Gaining access to our study's participants was of particular ease mainly due to perceived similarities: he is relatively young, moved to the Netherlands from an industrialized country to pursue higher education, and has connections to a large expatriate community through his work. The sample of this research is based on an open call for all expatriates residing in urban cities in the Netherlands aged fifteen to twenty-five years. We promoted this research through various social media platforms, including Facebook pages created for expats living in the Netherlands and on personal Instagram storylines. However, none of our study's informants were recruited from either social media platform. Participants became involved in our study through (1) snowball sampling or (2) UniBuddy, an online forum hosted by Utrecht University (UU) on its official website to ask current UU students questions relating to specific courses and student life on campus. The ethnographical field research was conducted during a seven-month period, from September 2018 to March 2019, in two urban cities in the Netherlands: Amsterdam and Utrecht. This study consists of thirty-one informants, of whom twenty-five self-identify as female and six as male.

The gender ratio of self-identifying female participants is four times greater than the number of self-identifying male participants. We sought to have a more balanced gender ratio; however, during snowball sampling, more female informants were willing to participate. We acknowledge that this gender ratio may reinforce the normative discourse of emotionality as authentically female; therefore, throughout our analysis, we employed a critical feminist approach to challenge and disrupt the conventional definition of the "emotional woman." The reluctance of male-identifying participants to join the study may also be indicative of hegemonic norms of masculinity that inhibit young professional males from reflecting on the embodied and emotional fragilities of their international lifestyles.

Thirty participants is a key threshold established in the grounded theory literature to secure theoretical saturation of emerging themes (Vasileiou et al. 2018). At the moment of fieldwork, the informants had been living in either Amsterdam or Utrecht for anywhere between four weeks and six years. The number of participants hailing from each of the following continents varied: Africa (two); Asia (six); North America (seven); and Europe (sixteen). The majority of our study's informants obtained legal residence status through student visas, whereas others were on their parents' visas or job hires. Throughout this article, we include the self-identification narratives of the participants to highlight their individually unique positionalities and nuanced pursuit of transnational intimacy.

Ethical considerations were of utmost importance. We had previously established positive relationships with a number of our study informants. It was important that we gained and maintained the trust of those whom we did not previously know. We heavily focused on our language when communicating who we were and our research project aims to eliminate any perceived power hierarchies (researcher vs. participant), which can greatly affect trust. Once we ensured that each informant was aware of their participation rights, we obtained written consent to begin the interview, and consent was provided by parents/guardians for minors. All interviews were in English as all informants were com- 
fortable and confident in speaking English. Each participant was asked to suggest a pseudonym to remain anonymous and to protect their identity. Consent was sought from each informant prior to publishing their photos. For individuals in photos from whom we did not obtain consent, we blurred their faces. To further anonymize our study participants, only approximations of their ages are provided.

With permission, interviews were recorded. We transcribed verbatim, coded, and thematically analyzed the interview transcripts and photos using NVivo, the qualitative data analysis computer software, while keeping in line with our commitment of employing a grounded theory approach. We used the emerging themes to organize the foundation of our empirical findings. This article is part of a larger research project that compares digital practices of young asylum seekers and expatriates in the Netherlands (see Leurs 2017).

\section{SETTING THE TERMS}

In line with our informants' self-identifications, we use the label "expatriate" in this article. For example, Sophie, an eighteen-year-old from Belgium, states "because that's what I've been labeled as, I guess. ... I can accommodate easily to every single culture. And I don't have one home, that's what expat means to me, I guess." However, categories of human mobility have taken up specific value-laden meanings. Expatriates is a common term in mobilities research, whereas the category of migrants is more prominent in research on people who are forcibly on the move or who are commonly seen as "labor migrants." This divergent focus has been questioned for reinforcing distinctions between privileged and marginalized mobile populations. However, with growing awareness of "mobility justice" (Sheller 2018), the politics of immobility, borders, and power hierarchies also receive growing attention among mobility scholars. While we here use the label of expatriate when referring to informants, this does not preclude us from drawing on critical migration scholarship.

Young adult expatriates do not necessarily conform to the common figure of a mobile "Western-elite" competing, performing, and benefiting in an "elitist global economy" (Rodriguez and Ridgway 2018). Oftentimes, the discourses that surround the notion are entangled in the concept of race and nationality. Whiteness is often wrapped up in expatriate privilege discourses. Investigating expatriate communities residing in former British colonies, Pauline Leonard (2010) explores the intersections of migration, race, gender, organizations, and work. She reveals the complexities and fragilities of white privilege that are often tied to the notion of expatriates. Although our case study is not situated in a former colony but in a colonial center, Leonard's empirical work reveals how we must stay attentive to complexities in the constructions of whiteness imbued in the notion of expatriate. In addition, Sarah Kunz (2016) states, "expatriate national identities can still be grounded in historical notions of racial and cultural superiority"; thus, the term can express "itself in everyday racisms and wider discourses of cultural difference that prescribe a broad range of strategies to 'manage' the local in daily life" (95). In other words, expatriates hailing from industrialized countries have supposed access to economic and social capital due to the privilege inherent in their whiteness. There is a danger in academic scholarship when using certain terms without questioning and interrogating their often taken-for-granted assumptions. When failing to do so, academics run the risk of (re)producing, even rein- forcing, certain meanings.

Expatriate as a discrete category fails to recognize the ambiguities and conceals the subjectivities of migrants themselves. Rather than being "treated as a 'category of analysis' available as a straightforward a priori conceptual frame," expatriateness as a performed and affective category itself should be "the object of analysis" (Kunz 2016, 96). Instead of assuming that expatriate denotes a particular kind of migrant, such as a highly skilled migrant from the (white) West, there is an urgency to further investigate the notion and (re)conceptualize it as a "category of practice that amongst other things expresses and performs a certain migrant subjectivity and describes certain locations or aspirations to position oneself within various local and global political and economic formations" (Kunz 2016, 96-97). Thus, the core of such processes will bring to the fore the "complex configurations of racialisation, class, nationality and gender, which are inherently related to the various instabilities and ambiguities of the notion expatriate itself" (Kunz 2016, 97). By doing so, we stay attentive to the unique situatedness of each young adult expatriate in our study.

\section{REFLEXIVITY AND POSITIONALITY}

The fieldwork process demands that we, the author duo as a cross-cultural team, reflect on how we negotiated our insider/outsider status within the communities we studied with. As Sharan Merriam et al. argue, insider/outsider statuses are not easily delineated and carry advantages and disadvantages that can be considered through concepts of positionality, power, and representation: "the reconstruing of insider/outsider status in terms of one's positionality visà-vis race, class, gender, culture and other factors, offer us better tools for understanding the dynamics of researching within and across one's cultures" (Merriam et al. 2001, 405). The first author is a biracial, self-identifying gay young adult expatriate who has been living in Amsterdam since June 2016. He studied in the Netherlands and continued his academic career as a junior researcher. The second author is a Netherlands-born, white, hetero tenured assistant professor. He is a first-generation student, and he grew up reflecting upon his privileged position through interacting with young mobile subjects who were living at a refugee camp in the village where he grew up. Those experiences he translates in his research practice, in seeking to combine creative, participatory, and digital methods to allow informants to have a say over how they are represented. As a result, both researchers share certain identifications and experiences with their informants, including age, generation, sexuality, race, nationality, and/or location, while others contrast, offering moments of recognition as well as reminding us of uneven power.

For example, during fieldwork the first author found himself reflecting upon his own experiences of mediating intimacies across geographical borders and situatedness as a middle-class mobile subject. Oftentimes, he drew from his own transnational digital intimacy experiences to help guide the research informants to reflect deeper on their own. Sometimes their responses evoked such strong bodily sensations; he felt he could relate to them so closely. He vividly remembers the interview with Sarah, a twentythree-year-old from Iran: when she shared a personal experience involving her mother, he began to cry. Her story resonated with him, and in that moment, he felt the line blur between being a researcher and a friend. He wanted to console her and to also be comforted, but he knew it 
was neither of their positions to do so. Here, we turn to Sneja Gunew (2009) and her "decolonising affect theory" where she states but rightfully questions, "the degree to which one may be permitted to display emotion depends on one's social status" $(2009,24)$. The aforementioned experiences raised pivotal ethical questions, including: What are the pros and cons of being an insider to a community under study? When a researcher resonates with the research topic and identifies closely with the informants, how do they maintain the line between professional and personal? Where does that line need to be drawn, and at what point must that line be created? In fact, does the line need to exist? These are questions we asked ourselves, particularly after the fieldwork period ended, and informants expressed desires to maintain friendships in wanting to meet for coffee or a bite to eat.

The emerging patterns from the data structure our empirical findings into two paradoxes of transnational digital intimacy practices: (1) moving toward and away from digital technologies and polymedia environments; (2) navigating home-making, homesickness, and senses of belonging.

\section{EMPIRICAL FINDINGS}

In this section, we analyze empirical examples of how young adult expatriates practice and perform transnational digital intimacies through various polymedia environments. All of our study's informants use a smartphone for work and entertainment and to keep in contact with their family, friends, or romantic partners living in their respective homelands. Our study's informants use different social media apps and platforms including WhatsApp, Instagram, FaceTime, Twitter, Snapchat, Line, Telegram, and WeChat, each of which offer their own unique combination of visual, aural, and haptic affordances. The young adult expatriates who participated in this study expressed the importance of their smartphone and social media apps and platforms through which they forge and sustain contact with their key transnational connections. For instance, Mike appreciates having the internet on his smartphone so he can talk to his family: "I love the internet. It allows me to stay connected to the people I love. Because I'm here, they're somewhere else. Even with my family [my grandparents] in the Philippines. I can talk to them and I can keep in contact with my grandma and my grandpa. And they love seeing my face from the video call.” For other participants like Isabelle, a twenty-two-year-old from the United States, owning and using a smartphone is a nonnegotiable when living internationally, not only for her but for her parents as well: "I think my parents would freak out, over here if I didn't have a phone, that's the whole reason they bought me the new phone [before moving to the Netherlands].”

\section{MOVING TOWARD AND AWAY THROUGH TRANSNATIONAL DIGITAL INTIMACY PRACTICES}

Early research on family relationships argued that physical face-to-face interactions are key to experience co-presence. To counter that argument, Madianou (2016) brought forward the notion "ambient co-presence" to elucidate the idea that digitally mediated connections are no less symbolic or meaningful in comparison to physical contact; it refers to the distinct ways people can relate across distance through new registers. The role of direct communication through text messages, whether through SMS, WhatsApp, Line, or Telegram, plays an important role in maintaining close and intimate transnational relationships. Ambient copresence helps SRB, a twenty-four-year-old from the Canary Islands, keep in contact with her best friends, who live in the Canary Islands: "On WhatsApp I have this group of my eight girlfriends from back home, which we speak a lot through it." For SRB and her friends, maintaining a close bond does necessitate daily communication; they send text messages "whenever anyone has something interesting to say." As Alinejad (2019) states: "constant digital communication need not produce intimacy, just as not all silences signify emotional distance" (2). Thus, one-to-one direct communication via text messaging may reproduce the feelings of intimacy and interconnectedness that physical faceto-face communication often does.

Something that the majority of our study's respondents almost invariably associated voice calling and videotelephony products such as FaceTime with were words such as "intense," "closeness," and "intimate." If, for example, Jessica, a twenty-year-old from the United States, wants to discuss minor day-to-day details with her transnational connections, then she deliberately chooses to send text messages: “...text is just small things like this happened and that happened." However, she opts to audio call when the topic of conversation is more meaningful and demands people's undivided attention: "I really talk and explain things... Sometimes talking is a little bit awkward but no, on the phone I really share more like my emotion, what I'm thinking and how I'm feeling." Similar to Jessica, Sophie, an eighteen-year-old from Belgium, sends text messages via WhatsApp to her friends and also calls them if the conversation requires more attention: "When I wanna say something more serious, I think I'll WhatsApp someone and be like, yo, like, can you call or something or I'll send a voice memo." While both Jessica and Sophie strategically select between the various affective technological affordances (Bareither 2017; Twigt 2018; Witteborn 2018) based on the seriousness of the conversation, Sophie also chooses which social media app, platform, and affordance to use depending on who she talks to. For example, she explains that both she and her mother prefer the audiovisual affordance of FaceTime not only out of convenience but for the ease with which they are able to clearly explain and communicate to one another: "I think also for her to explain herself. She's just, yeah, I don't know, just better on video.” Sophie describes her relationship with her family as "a team." Perhaps it can be understood that her and her mothers' previously established close-knit relationship with each other is also what drew them to use this particular app and affordance. Nevertheless, it is clear that for Sophie, videotelephony apps help her maintain and sustain a transnational connection with her mother.

Though the visual, aural, and haptic affordances of the smartphone and some social media apps and platforms can stimulate positive affects and emotions, such as happiness, joy, and confidence, transnational co-presence (Diminescu 2020) can become overwhelmingly intense, both affectively and emotionally. Isabelle says: "There's more emotion, I guess, when there's video, because you can really see their expressions and what they're saying with their words, which I like." Many of our study's informants shared that the affordances of video telephony platforms-being able to hear and see their transnational connections in real time-make it feel as if they are in their physical proximity: "It feels more like in real life" (Sophie); "It's as close as her being next to me as I think I'll get living across two countries" (Jessica); and “I almost feel like I'm in the same room with my mom or with them at that moment" (Bee). The nar- 
ratives of our study's participants show the affective transitions resulting from transnational digital intimacy practices are various and highly ambiguous. The majority of informants expressed strong feelings-a daily compulsion-of needing to maintain an emotional connection to their key transnational connections, thus feeling a sense of "ontological security” (Georgiou 2013). Here ontological security through transnational connectivity does not come naturally, as Ophelia, a twenty-five-year-old from Germany, notes: "Like in the beginning, I really had to get used to it." Because from the outset, "virtually no one knows how to do intimacy” (Berlant 1998, 282), establishing new routines of intimacy practices involves acquiring new skills. Over time, Brian Massumi argues, routine affective practice "gives the body's movements a kind of depth that stays with it across all its transitions-accumulating in memory, in habit, in reflex, in desire, in tendency" $(2015,4)$.

A multiplicity of transnational digital intimacy practices was observed, which seem to revolve around understudied ambiguities of connection and disconnection (Sundén 2018): maintaining co-presence revolves around a paradox of pulling close to significant others at times and pushing away at different moments. This paradox can be teased out following Ahmed's (2004) theorization of the cultural micropolitics of emotion: "emotions are relational: they involve (re)actions or relations of 'towardness' or 'awayness' in relation to such objects” (8). Enabling a sense of moving towardness, SRB shares a time when she practiced cybersex with her romantic partner:

SRB: Yeah, my most memorable moment was being able to see someone in the distance and kind of like have sex with them through FaceTime. I have this one memory, maybe one of the first times that it happened. Doing it, what not, whatever that was. It just felt really weird. We just looked at each other like, wow. That was like, intense. But it was through the phone. And it was-my heart was beating so fast, because it was just a really strange feeling, a really strange feeling. However, it was also like kind of scary, like Black Mirror kind of shit....

Because you are just with yourself and then with the phone in your hand. It's pretty scary futuristic narcissist, somehow.

Q: Did you feel alone in that moment, or did you feel like you were with someone?

SRB: Fifty-fifty. That's what I'm saying. It was like really powerful and intense, the fact that we were able in this century to get to do that with each other. But at the same time, I was on my own in my house and after like twenty minutes he just hung up and you're on your own. So it's a weird feeling. But you kind of get used to it.

Transnational mobility as a result of globalization is commonly thought to threaten intimate connections among romantic partners, as partners have to rely on digital technologies to forge and sustain sexual relationships across distance. Intimate romantic relationships are typically associated with the private sphere of the physical home, a space that is thought to provide protection from global capital and the ramifications of globalization. However, our informant's experiences illustrate how polymedia environments allow romantic relationships to stretch the geometries of intimacies beyond geographical borders. SRB spoke of how she became intimate through the digital, capturing how "sexualities may be de/re/constructed through online performativity" (Hillis 2009, 210). Such transnational "rituals of transmission" $(2009,5)$ clearly indicate how physical bodies are not detached from digital practices. Globalizing intimacy through the smartphone expands SRB's opportunity to rearticulate sexual intimacy practices into the virtual; thus, what were previously body-and-flesh encounters are now transformed into virtual erotic connections and, arguably, embodied forms of performing love, care, and sex through the digital (Valentine 2006). For SRB, her desire for an erotic connection is frustrated by distance and the absence of physical touch. FaceTime affords SRB the space to perform cybersex with her romantic partner, conceptualized as part of sexual and intimate "digital media communication practices" (Dobson 2018, 94). For Ahmed, "what moves us, what makes us feel, is also that which holds us in place" $(2004,11)$; the intimacies of cybersex, as illustrated by SRB's experience, show us the paradoxical affective bodily transitions involved in digitally moving toward others.

The erotic possibilities afforded by FaceTime offer SRB embodied feelings of connection, warmth, and belonging-actioning her movement "toward" her partner through her smartphone-though, paradoxically, she is left with a feeling of greater absence, accentuating her longing for physical touch; ultimately, because "individuals still often prefer to act locally!” (Valentine 2006, 387).

Performing digital intimacies can simultaneously produce negative affective intensities such as guilt, loneliness, and sadness, as illuminated by Isabelle, who moved from the United States to the Netherlands to attend university:

$$
\begin{aligned}
& \text { [I] had to tell them [my parents]... I don't want you to } \\
& \text { FaceTime video me when you're with my brother and } \\
& \text { his wife at the house, like having a nice family dinner... } \\
& \text { or family party, get together... [I]t makes me feel left } \\
& \text { out, kind of. So, they actually created their own group } \\
& \text { chat... I feel more left out when I see what's happening } \\
& \text { [via FaceTime] when I'm not there. I guess for me if it's } \\
& \text { something like that, the less I see, the happier I feel. }
\end{aligned}
$$

Isabelle has a mother, a father, and a brother living in another country, all of whom she has an extremely close bond with (figure 1). The everyday, ritualistic practices Isabelle maintains with her family at times enable her to feel relatively the same familial bond as if she were in their physical proximity. However, she strategically chooses not to FaceTime her family during family dinners as the audiovisual affordances of FaceTime for her evoke strong negative bodily sensations alongside emotions of sadness, all of which make her feel like she is missing out on a pastime she loved to take part in. Practicing disconnectivity allows us to reconsider the affective workings of transnational digital intimacies. This is an important corrective because, as Sundén reminds us, the "discussion of affective relationality is quite densely steeped in a language of capacity, enhancement, and increase ... what seems to be missing is an acknowledgement of the affective qualities of the disconnect" $(2018,75)$.

The various emotional and affective intensities of mediated intimacies are in relation to the deliberate choices of polymedia environments and social media affordances that evoke different feelings of spatial proximity. Sometimes synchronizing temporalities creates feelings of connectedness and helps to forge and sustain emotional bonds across borders, though the feelings of being "there" while physically being "here" can, for some, become too intense. We see, at times, how young adult expatriates selectively choose distinct "affective affordances" of specific platforms (Twigt 2018, 2) to negotiate between forms of connectivity 


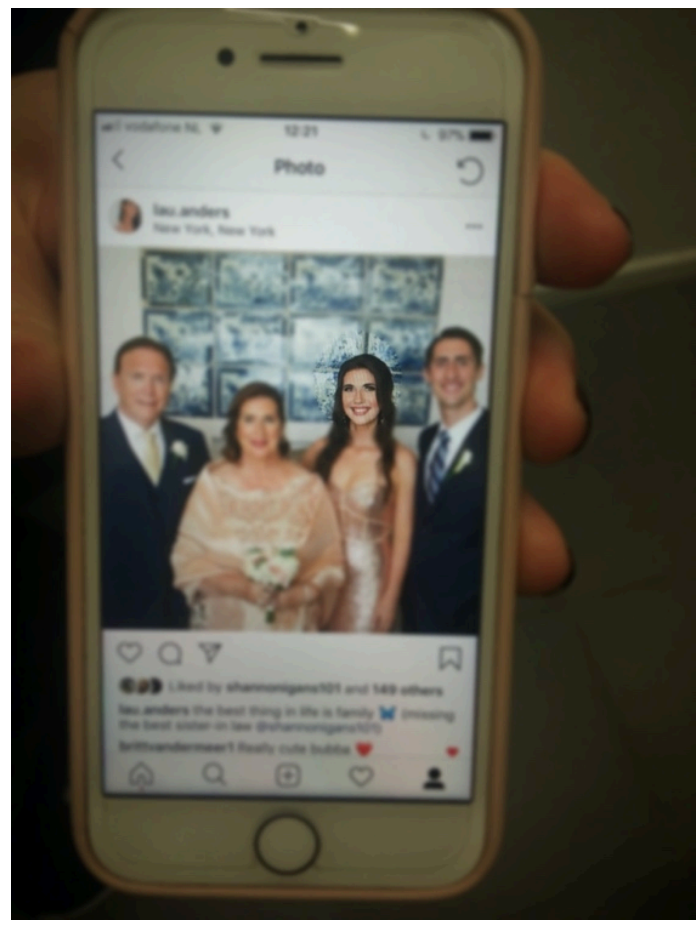

Figure 1. A photo Isabelle shared from her smartphone archive.

Left to right: Isabelle's father, her mother, Isabelle, and her brother attending her brother's wedding a day before she moved to the Netherlands.

and disconnectivity. Thus, young adult expatriates transform intimacies (Elliot and Urry 2010) to balance emotions and affects of transnational mobility and their desire to $\mathrm{cu}$ rate their preferred sense of co-presence.

\section{PARADOXES OF HOME-MAKING AND HOMESICKNESS}

This section discusses the complex intersections of young expatriates' on- and offline experiences. The majority of our study's informants combine their establishment of a new home in Amsterdam with feelings of homesickness and desires to return "home" to visit their family, friends, and romantic partners, and to return to familiar spaces such as bedrooms, cafés, and yoga studios, all of which are imbued with strong personal memories and embodied sensations. We argue that home is a heterogeneous discursive and emotional practice, most commonly known to media scholars as "home-making" (Bareither 2017). Translating and adapting the notion of doing digital family through the mediation of technology (Taipale 2019), our study's informants do home-making through several transnational digital intimacy practices. They reminisce about previous histories of contact with places, spaces, and people in a number of ways: (1) through engaging with their archive of images in their smartphones; and (2) by exchanging photos and placing video calls with key transnational connections.

When Chloe, an eighteen-year-old from Spain, longs for the warm summer weather of her seaside hometown, she sometimes looks at photos in her smartphone photo archive that show her at the beach. When she reminiscences about those beach days, she feels that "it's an amazing view. The beach is amazing and the summer vibe, everyone is out. Everyone is happy, everyone is on vacation. It's just pure joy basically." Chloe has a strong "place attachment," a personal connection to a place that holds past memories, feelings, and emotions (Li and McKercher 2016). For Chloe, these photographs (figure 2) are imbued with meaning based on her affective and embodied personal experience(s) at that location (Serafinelli 2018). This "emotional practice" (Bareither 2017) of doing home-making-retrieving and reflecting upon photos from her smartphone pocket archive-helps her alleviate her feeling of homesickness; she is able to simultaneously relive, feel, and do home from a distance.

Home-making through photographic practices and video calls does not necessarily relieve feelings of homesickness for all of our study's informants. In his study of how overseas Filipino workers in Melbourne, Australia, deployed smartphone photography to perform digital intimacies across borders, Cabalquinto (2018) argues that the mobile photos are important content that is produced and circulated to connect transnational families. Both complementing and complicating this line of argument, Olivia, a nineteen-year-old from Indonesia, for example, exchanges mobile photography to do home-making but feels the pain of homesickness. Exchanging photos, Olivia explains, "makes me feel the distance. Because then you realize also that they're doing their own things and you're doing your own things and that they're so far away." Video calling can also evoke unpleasant affective experiences and "trigger that feeling [of homesickness]," as highlighted by Tiffany, a twenty-two-year-old from Kosovo, "because when you talk just in audio you don't have much connection but the other day I was talking with my mom and I saw the apartment and I saw this scenery and it reminded me of that." Other informants share relatively the same sentiment as Olivia and Tiffany. Take, for example, Bee, a twenty-one-year-old Indonesian, who moved to the Netherlands to attend university. She explains, "Sometimes you do Facetime and I have dogs at home and then when I see my dogs, it's just like, I want to be there." It is clear that the smartphone and certain affordances transform users' senses of locality and allow young adult expatriates to reground themselves in feelings of place-based and familial ontological security (Mor- 


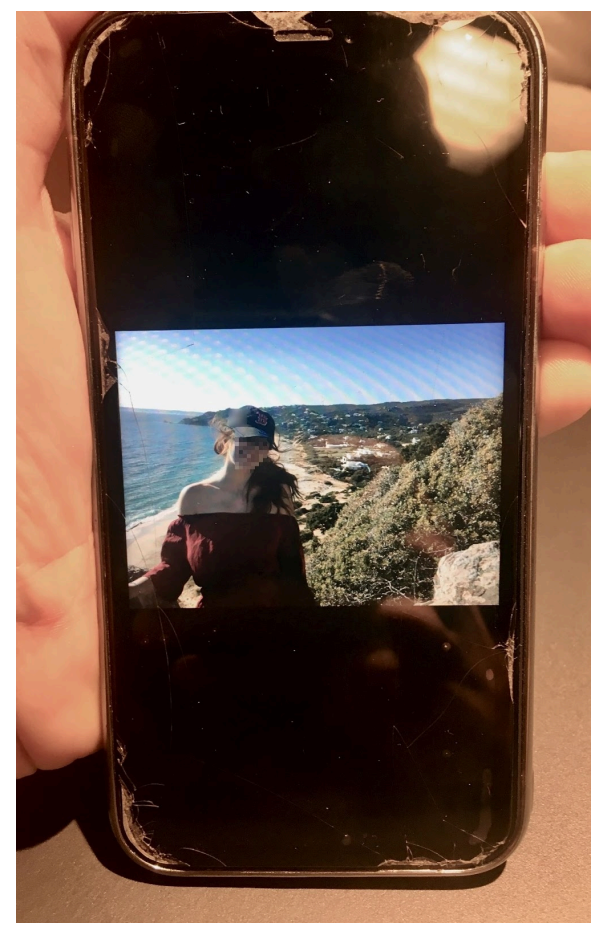

Figure 2. A photo Chloe shared from her smartphone archive.

Chloe at the beach near her home in Spain.

ley 2003). Furthermore, it is evident that there are several ways in which young adult expatriates seek to cope, adapt, adjust, or react toward/away from (Ahmed 2004; Elliot and Urry 2010) such by-products of globalization.

For some informants, like Elena and Isabelle, homemaking may not always stem from a desire to visit "home" but rather from feelings of normative obligation and expectations that may shape emotional precarity. In the cases of Elena and Isabelle, routine connections turn into limiting communicative regimes, as they experience forms of transnational surveillance. Elena, a nineteen-year-old from Romania, explains that she exchanges text messages with her mother every day, in the morning, at midday, and during the evening when she gets home from work. Though large time differences can put a strain on the synchronicity of transnational communications (Farshbaf Shaker 2018), there is only an hour's difference between Elena and her mother; thus, it makes it "easy for her to know what I'm doing." Elena recalls a time when she "forgot completely to text [my mother] for an hour after I already arrived home [from work]," and while she was in the shower, her flatmate received a call from Elena's mother wondering where she was: "she wants to know that I'm safe, because she got used to seeing me every day and she knew where I was all the time." As preexisting familial traditions become disrupted, forms of transnational digital surveillance can take shape. Consider Isabelle:

I guess if I'm really caught up in the moment and really enjoying myself with my friends and stuff, I don't really think of even using my phone. Not necessarily talking to them but it could be like two days where I've only sent one or two messages and my dad's like, what's going on. Because they have control of all my accounts, like not my accounts, but my bank accounts. So they can see that I'm doing things and having fun and they're like, well, you know, send us a picture.
Even though the digital domain is often heralded for increasing personal autonomy and offering space for experimentation, Elena and Isabelle discuss digital intimacy practices that are performed in the face of the private, disciplinary gaze of family, friends, and peers. With the notion of "intimate surveillance" $(2014,43)$, Dinah Hannaford captures how in transnational relations across distance, "the virtual presence" of absent loved ones "frequently represents a spectre of suspicion, control and surveillance" (ibid). Such digitally mediated transformations of family life-controlling relationship experimentation across distance-may disrupt the reinvention of personal values, practices, and lifestyles that globalization demands. In meeting the expectations of their key transnational connections, this form of surveillance, in turn, requires young, transnationally mobile adults to become negotiable, transformable, and flexible. It is argued that with the help of digital media, globalization supports the traditional pillars of social interaction and increasingly generates feelings of interconnectedness (Elliot and Urry 2010). Although Dana Diminescu (2020) highlights that every migrant experiences a "compulsion of proximity" (76), we find that young adult expatriates actively negotiate transnational communications to avoid the anxieties and emotional dilemmas generated by the transformations of intimacy. This finding ultimately echoes Amanda Wise and Selvaraj Velayutham's (2017) findings that in transnational social fields, "an array of affects such as shame, honour, pride, guilt, and obligation structure inter-subjective relationships" (116).

A number of informants at times choose to forgo the practice of home-making as it is complex and requires processes of negotiation and navigation (Chen, Butler, and Liang 2018). Rather, participants like Bee expressed that their motivation to disconnect was based on their perceived need to integrate into the local Dutch society. Integration is a complex concept in migration studies and even more of a convoluted lived experience for people who move. Accord- 
ing to Huan Chen et al. (2018), integration refers to mobile subjects who simultaneously maintain their original cultural practices, beliefs, and values while looking for daily interaction with other cultures; here, we are referring to the national and local Dutch community. By immersing herself in a new cultural context-intentionally digitally disconnecting from people, places, and things back "home" and seeking daily offline interaction with other cultural communities, both Dutch and international-Bee, arguably, is actively pursuing a level of integration into the local Dutch community:

I don't really keep in touch with a lot of them anymore... because I feel like I don't-I've nothing against them, but it's more of like, if I live here, I have my friends here. It's not that I forget about them, but if I keep living this way, talking to them all the time, I'm not living here with the friends I have here now.

While keeping our commitment to follow a non-digitalmedia-centric approach, we reflect upon the "third culture kid" outlook, which young expatriates are expected to develop as a result of their mobile life trajectories (Pollock and Reken 2009). Some informants express their global cosmopolitan outlook: "Because I've moved around my whole life, I'm comfortable in pretty much every single culture in a way" (Laura). Laura, an eighteen-year-old born in Slovakia and raised in Oman, is used to establishing a "home" as part of her mobile lifestyle, and she feels a sense of belonging in Amsterdam: "I just feel like I blend in more, because of my personality as well and the way I look and the way I dress"; “... Because I'm tall, Caucasian, blond, blue eyes.” Despite not being born in the Netherlands, it is evident that Laura's perceived position of whiteness is a marker of "sameness" and offers a sense of privilege and belonging-feelings of "home"-within the local Dutch community. Here, it is important to recognize that feelings of "home" are closely aligned with race and nationality, for these are axes that to some extent limit young adult expatriates' ability to experience home away from home.

Home-making is further compounded by offline interethnic encounters between expatriates and established members of the Dutch and Amsterdam community. To their frustration, some informants found that their nationality hindered access to student accommodation. Eventually, Tiffany found an apartment where she is happy to live. During our interview, she chose to show us a picture emphasizing finding her place as one of her highlights since moving to the Netherlands (figure 3). She experienced challenges settling into the Netherlands and meeting Dutch locals. According to a recent study of international students living in the Netherlands issued by three student organizations-Interstedelijk Studenten Overleg (ISO); het Erasmus Student Network Nederland (ESN); and hebben samen met de Landelijke Studentenvakbond (LSVb) -72 percent of the 10,002 international student respondents felt that student housing could be more organized (IAMEXPAT 2019). A further 44 percent found the housing experience to be stressful (IAMEXPAT 2019). Tiffany shared that she had a difficult time finding housing due to her coming from abroad: "You would see in the Facebook and other sites there were rooms available but you will also see with caps lock written: 'NO INTERNATIONALS.' So, I guess it was last chances for international students to get accommodation.” Tiffany's experience demonstrates that housing discrimination exists on the basis of nationality.

\section{CONCLUSIONS}

"What, exactly, has changed to facilitate intimacy at-a-distance as a growing pattern?” (Elliot and Urry 2010, 87).

This article has presented how young adult expatriates practice and perform digital intimacies through their smartphones as a point of departure to gain deeper insight into the emotional and affective consequences of transnational mobility. We propose the notion of transnational digital intimacy practices to call into question the notion of "expatriates” as supposed elite mobiles with global privilege. The label of "expatriate" tends to make us overlook how sociocultural categories of identity like age, race, nationality, gender, and sexuality hierarchically and differentially position individuals. This is crucial in understanding the affective and emotional experiences and processes between individuals (connoting group differences) and among individuals (connoting group similarities).

Drawing on thirty-one in-depth interviews and photo elicitation, we argue how transnational digital intimacy practices blur the boundaries between private and public mediated life, material-digital forms of embodiment, and symbolic-affective registers of intimacy. Through the interviews, we aimed to highlight the paradoxical experiences of practicing and performing transnational digital intimacies. Intimacies are exchanges, relations, activities, and situations between bodies that affect and are affected regardless of the processes of mediation. Digital media allow for new forms of transnational digital intimacies that provide both young adult expatriates and their key transnational connections with often needed emotional support due to time-spatial proximity. This can help reduce and overcome feelings of isolation, segregation, and alienation, caused or exacerbated by transnational movement. However, as many digital migration scholars have highlighted, these emotional negotiations can be imbued with tension, further provoking feelings of loneliness, guilt, and shame (Cabalquinto 2018). In this article, we have therefore sought to tease out the paradoxes of transnational digital intimacies of young adult expatriates with a focus on gaining a clearer understanding of the positive and negative emotional and affective experiences, thus fostering "(re)actions or relations of 'towardness' or 'awayness'” (Ahmed 2004, 8) in the face of emotional precarity.

As this article has focused on critically examining the digital intimacy practices of young adult expatriates, future research can further explore the emotional and affective consequences of this capitalist push from the point of view of those who do not move but keep transnational connections with those who do. The performance of interpersonal connections through digital technologies is bidirectional; thus, this bidirectionality warrants an investigation into how the digital reconfigures intimacy for both mobile subjects and their family, friends, and romantic partners who remain in their respective homelands.

When seeking to account for the emotional consequences of mobility as a result of cultural globalization, the implications for evolving sexualities demands further scrutiny. Evidenced by Mike, who may have married his move to Amsterdam to attend university with his desire of his "newer-ing identity," we begin to question to what extent the global capitalist push or the "process of becoming” initiated his move. As Ken Plummer notes, the advance of global capitalism, digital technologies, and migration also results in "transformational sexualities" $(2015,40)$. Future research on transnational digital intimacies thus may broaden the scope beyond expatriate mobile subjects, and 


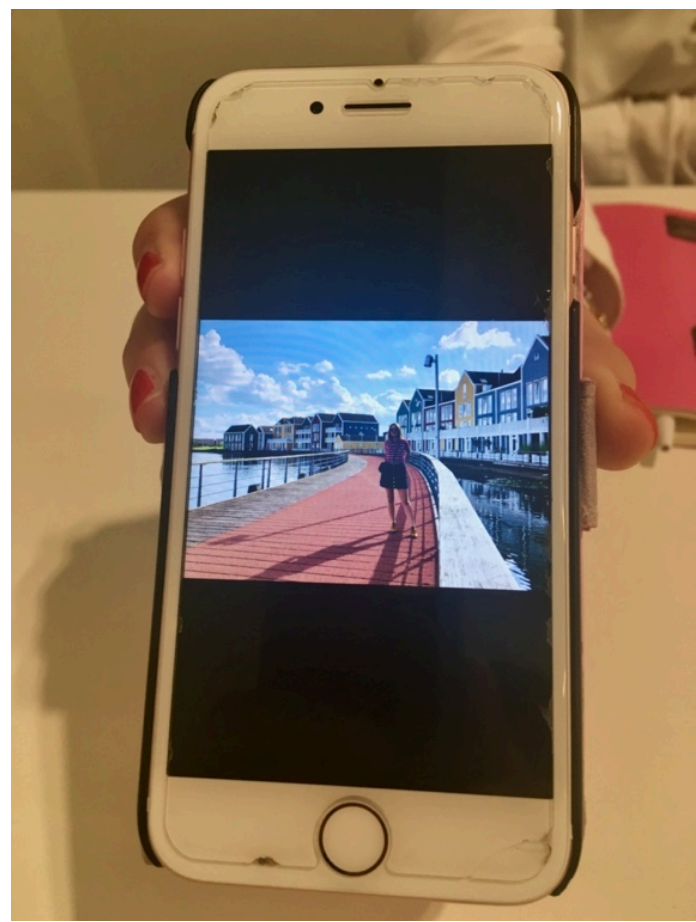

Figure 3. A photo Tiffany shared from her smartphone archive.

Tiffany posing in front of houses in her neighborhood.

empirically and conceptually, our understandings of transnationalism and digital intimacies can be further developed by acknowledging experiences and practices of nonnormative sexualities and nonbinary-identifying mobile subjects across the Global North and the Global South. This move is indispensable not only to avoid the traps of ethnocentrism and heteronormativity but also "to recognize that all people-be it queer migrants or not-are desiring subjects who navigate complex tangles of identity positions at multiple and interconnected geographical scales" (Sculz 2020, 229).

In conclusion, we write this article amid the unprecedented events of the coronavirus disease (COVID-19) pandemic. Many countries globally have responded to this crisis by enforcing partial or full lockdowns to help battle the spread of the novel virus. As people around the world are forced to isolate themselves from loved ones and friends, they are searching for ways to maintain their intimate relations through the digital. Platforms like Zoom, WhatsApp, Skype, and FaceTime have gained more currency in the recent news media for their ability to connect families, friends, romantic partners, and colleagues alike, both within and across geographical borders, as a means of connectivity. How does the digital reconfigure relationships during times of crises? Lynnette Arnold thus rightly argues that we can find "tips for staying connected during coronavirus, from migrants who live far from family"; "separation, while new to most, is a fact of life for the world's migrants. Still, many sustain close relationships with relatives through years, even decades, of physical distance" (2020, np). Nonmigrants affected by the pandemic have lots to learn from mobile subjects who have developed a wealth of practical and affective situated community knowledge about the paradoxes of doing digital intimacy across distance.

\section{AUTHORSHIP CONTRIBUTIONS}

- Contributed to conception and design: JP, KL

- Contributed to acquisition of data: JP

- Contributed to analysis and interpretation of data: JP, KL

- Drafted and/or revised the article: JP, KL

- Approved the submitted version for publication: JP, KL

\section{ACKNOWLEDGMENTS}

We are grateful to the interviewees for sharing their experiences. The authors benefited from suggestions by Amanda Paz Alencar, Christine Quinan, Payal Arora, and Sander de Ridder, copy-edits from Erica Olsen as well as from input received when presenting earlier versions of this article at Etmaal Netherlands Communication Studies Conference 2019; European Communication and Education Conference 2019; International Association for Media and Communication Research 2019; and Digitized Global Mobilities (UGlobe) 2019. The research master's students of Utrecht University's Research Design II provided invaluable feedback. We also appreciate comments provided by D'An Knowles Ball, editor of the MediaCommons Field Guide on the theme "A Digital Space to Call Home." We contributed an early reflection on our fieldwork to this guide.

\section{FUNDING INFORMATION}

This research was supported by the Dutch Research Council (NWO) Veni grant "Young connected migrants. Comparing digital practices of young asylum seekers and expatriates in the Netherlands," project reference 275-45-007 (2016-2019). 


\section{COMPETING INTERESTS}

The author(s) declared no potential conflicts of interest with respect to the research, authorship, and/or publication of this article.

\section{AUTHOR BIOGRAPHIES}

Jeffrey Patterson is currently a (post)graduate student at the Netherlands Research School of Gender Studies, Utrecht University, the Netherlands. He works as a research assistant for Prof. Sandra Ponzanesi covering issues regarding the digital and mediation, migration and mobility, and emotion and affect. He is currently in pursuit of a funded $\mathrm{PhD}$ research position in the field of digital migration.

Koen Leurs is assistant professor in gender and postcolonial studies, Graduate Gender Program, Department of Media and Culture, Utrecht University, the Netherlands. He chairs the European Communication Research and Education (ECREA) Diaspora, Migration and the Media section. Recently, he coedited the Sage Handbook of Media and Migration and journal special issues on "Forced Migration and Digital Connectivity" for Social Media + Society and "Connected Migrants" for Popular Communication. His next monograph is titled Digital Migration (Sage, forthcoming 2021). 


\section{REFERENCES}

Ahmed, Sara. 2004. The Cultural Politics of Emotion. London: Routledge.

Alinejad, Donya. 2019. "Careful Co-Presence: The Transnational Mediation of Emotional Intimacy.” Social Media + Society 5 (2): 205630511985422 . http s://doi.org/10.1177/2056305119854222.

Arnold, Lynette. 2020. “4 Tips For Staying Connected During Coronavirus, From Migrants Who Live Far From Family." Last Modified April 3 2020. https://thec onversation.com/4-tips-for-staying-connected-durin g-coronavirus-from-migrants-who-live-far-from-fam ily-134362? utm source=facebook \&utm medium=byli nefacebookbutton.

Awad, Isabel, and Jonathan Tossell. 2019. "Is the Smartphone Always a Smart Choice? Against the Utilitarian View of the "Connected Migrant."” Information, Communication \& Society, September, 1-16. https://doi.org/10.1080/1369118x.2019.166845 6.

Bareither, Christoph. 2017. “'That Was so Mean :D’ Playful Virtual Violence and the Pleasure of Transgressing Intersecting Emotional Spaces." Emotion, Space and Society 25 (November): 111-18. https://doi.org/10.1016/i.emospa.2016.12.005.

Beck, Ulrich, and Elisabeth Beck-Gernsheim. 2015. “Distant Love." In Personal Life in the Global Age. Cambridge: Polity.

Belabas, Warda, Jasper Eshuis, and Peter Scholten. 2020. "Re-Imagining The City: Branding MigrationRelated Diversity.” European Planning Studies 28 (7): 1315-32. https://doi.org/10.1080/09654313.2019.170 1290.

Berlant, Lauren. 1998. "Intimacy: A Special Issue.” Critical Inquiry 24 (2): 281-88. https://doi.org/10.108 6/448875.

---. 2011. Cruel Optimism. Durham: Duke University Press. https://doi.org/10.1215/9780822394 $\underline{716}$.

Bourdieu, Pierre. 1984. Distinction: A Social Critique of the Judgement of Taste. Cambridge: Harvard University Press.

boyd, danah. 2014. It's Complicated: The Social Lives of Networked Teens. New Haven: Yale University Press.
Cabalquinto, Earvin Charles. 2018. “Ambivalent Intimacies: Entangled Pains and Gains Through Facebook Use in Transnational Family Life.” In Digital Intimate Publics and Social Media, 247-63. London, UK: Springer International Publishing. https://doi.or g/10.1007/978-3-319-97607-5_15.

Cabañes, Jason Vincent A. 2019. “Information and Communication Technologies and Migrant Intimacies: The Case of Punjabi Youth in Manila.” Journal of Ethnic and Migration Studies 45 (9): 1650-66. https://doi.org/10.1080/1369183x.2018.145 $\underline{3790}$.

Calhoun, Craig. 2003. “'Belonging'in the Cosmopolitan Imaginary.” Ethnicities 3 (4): 531-53. $\underline{\mathrm{h}}$ ttps://doi.org/10.1177/1468796803003004005.

Candidatu, Laura, Koen Leurs, and Sandra Ponzanesi. 2019. “Digital Diasporas: Beyond the Buzzword.” In The Handbook of Diasporas, Media, and Culture, 31-47. NJ: John Wiley \& Sons, Inc. https://doi.org/1 0.1002/9781119236771.ch3.

CBS. 2018. “Centraal bureau voor statistiek statline.” https://www.cbs.nl.

Chen, Huan, Earlesha Butler, and Xuan Liang. 2018.

"Facilitating or Impeding Acculturation: A Qualitative Study on Mobile Social Messaging in First-Generation Chinese Immigrants' Everyday Lives." Journal of Intercultural Communication Research 47 (6): 510-29. https://doi.org/10.1080/1747 $\underline{5759.2018 .1503192 .}$

Costa, Elisabetta, and Laura Menin. 2016. "Introduction." Middle East Journal of Culture and Communication 9 (2): 137-45. https://doi.org/10.116 3/18739865-00902002.

Crul, Maurice. 2016. "Super-Diversity vs. Assimilation: How Complex Diversity In MajorityMinority Cities Challenges the Assumptions of Assimilation." Journal of Ethnic and Migration Studies 42 (1): 54-68. https://doi.org/10.1080/136918 3x.2015.1061425.

Diminescu, Dana. 2020. "Researching the Connected.” In The Sage Handbook of Media and Migration, 74-78. London, UK: SAGE Publications Ltd. https://doi.org/10.4135/9781526476982.n12. 
Dobson, Amy Shields. 2018. “Sexting, Intimate and Sexual Media Practices, and Social Justice.” In Digital Intimate Publics and Social Media: Towards Theorising Public Lives on Private Platforms, edited by Amy Dobson, Brady Robards, and Nicholas Carah, 93-110. London, UK: Palgrave Macmillan.

Dobson, Amy Shields, Brady Robards, and Nicholas Carah. 2018. "Digital Intimate Publics and Social Media: Towards Theorising Public Lives on Private Platforms." In Digital Intimate Publics and Social Media: Towards Theorising Public Lives on Private Platforms, edited by Amy Dobson, Brady Robards, and Nicholas Carah, 3-27. London, UK: Palgrave Macmillan.

Elliot, Anthony, and John Urry. 2010. Mobile Lives. New York, NY: Routledge.

Employment Conditions Abroad Limited (ECA). 2019. "Global Liveability Report Reveals Which Cities Offer the Best Quality of Life for Europeans Abroad." Last Modified February 11, 2020. https://www.eca-internat ional.com/news/february-2020/global-liveability-repo rt-reveals-which-cities-off.

Farshbaf Shaker, Sahel. 2018. "A Study of Transnational Communication Among Iranian Migrant Women in Australia." Journal of Immigrant \& Refugee Studies 16 (3): 293-312. https://doi.org/1 $\underline{0.1080 / 15562948.2017 .1283078 .}$.

FinAccord. 2018. "Global Expatriates: Size, Segmentation and Forecast for the Worldwide Market." Last Modified July 12, 2018. https://www.fin accord.com/getattachment/Home/About-Us/Press-Re leases/Global-Expatriates-Size,-Segmentation-and-F orecas/press_release_global_expatriates_size_segment ation_forecast_worldwide_market.pdf.aspx?lang=enUS.

Georgiou, Myria. 2013. “Seeking Ontological Security Beyond the Nation: The Role of Transnational Television.” Television \& New Media 14 (4): 304-21. https://doi.org/10.1177/1527476412463448.

Gregg, Melissa, and Gregory J. Seigworth, eds. 2009. The Affect Theory Reader. Durham \& London: Duke University Press. https://doi.org/10.1215/9780822393 047.

Gunew, Sneja. 2009. "Subaltern Empathy: Beyond European Categories in Affect Theory." Concentric: Literary and Cultural Studies 35 (1): 11-30.

Hannaford, Dinah. 2014. "Technologies of the Spouse: Intimate Surveillance in Senegalese Transnational Marriages.” Global Networks 15 (1): 43-59. https://doi.org/10.1111/glob.12045.
Heidkamp, Birte , and David Kergel. 2017. "Precarity and Social Media from the Entrepreneurial Self to the Precariatised Mind.” In Precarity within the Digital Age. Prekarisierung und soziale Entkopplung transdisziplinäre Studien, edited by Birte Heidkamp and David Kergel, 99-114. Wiesbaden: Springer VS.

Hillis, Ken. 2009. Online a Lot of the Time. Ritual, Fetish, Sign. Durham, NC: Duke University Press. http s://doi.org/10.1215/9780822392224.

Hofhuis, Joep, Katja Hanke, and Tessa Rutten. 2019. "Social Network Sites and Acculturation of International Sojourners in the Netherlands: The Mediating Role of Psychological Alienation and Online Social Support.” International Journal of Intercultural Relations 69 (March): 120-30. https://do i.org/10.1016/j.ijintrel.2019.02.002.

Hynnä, Kaisu, Mari Lehto, and Susanna Paasonen. 2019. "Affective Body Politics of Social Media." Social Media + Society 5 (4): 205630511988017. https://doi.o rg/10.1177/2056305119880173.

IAMEXPAT. 2019. https://www.iamexpat.nl/educatio n/education-news-1.

Invest in Holland. 2020. "Uncertainty of Brexit Remains, More Companies Choose the Netherlands'.” https://investinholland.com/news/uncertainty-of-bre xit-remains-more-companies-choose-the-netherland s/.

Jamieson, Lynn. 2011. “Intimacy as a Concept: Explaining Social Change in the Context of Globalisation or Another Form of Ethnocentricism?" Sociological Research Online 16 (4): 1-13. https://do i.org/10.5153/sro.2497.

Kaufmann, Katja. 2020. "Mobile Methods: Doing Migration Research with the Help of Smartphones." In The Sage Handbook of Media and Migration, 167-79. London, UK: SAGE Publications Ltd. https://d oi.org/10.4135/9781526476982.n22.

Kunz, Sarah. 2016. "Privileged Mobilities: Locating the Expatriate in Migration Scholarship." Geography Compass 10 (3): 89-101. https://doi.org/10.1111/gec 3.12253.

Leonard, Pauline. 2010. "Work, Identity and Change? Post/Colonial Encounters in Hong Kong." Journal of Ethnic and Migration Studies 36 (8): 1247-63. http s://doi.org/10.1080/13691831003687691.

Leurs, Koen. 2017. “Communication Rights from the Margins: Politicising Young Refugees' Smartphone Pocket Archives." International Communication Gazette 79 (6-7): 674-98. https://doi.org/10.1177/174 $\underline{8048517727182 .}$. 
---. 2019. "Transnational Connectivity and the Affective Paradoxes of Digital Care Labour: Exploring How Young Refugees Technologically Mediate CoPresence.” European Journal of Communication 34 (6): 641-49. https://doi.org/10.1177/02673231198861 66.

Li, Tingting Elle, and Bob McKercher. 2016. "Effects of Place Attachment on Home Return Travel: A Spatial Perspective.” Tourism Geographies 18 (4): 359-76. https://doi.org/10.1080/14616688.2016.1196 238 .

Madianou, Mirca. 2014. "Smartphones as Polymedia." Journal of Computer-Mediated Communication 19 (3): 667-80. https://doi.org/10.1111/jcc4.12069.

- - - 2016. "Ambient Co-Presence: Transnational Family Practices in Polymedia Environments." Global Networks 16 (2): 183-201. https://doi.org/10.1111/glo b.12105.

Marino, Sara. 2019. “Cook It, Eat It, Skype It: Mobile Media Use in Re-Staging Intimate Culinary Practices Among Transnational Families." International Journal of Cultural Studies 22 (6): 788-803. https://do i.org/10.1177/1367877919850829.

Massumi, Brian. 2015. The Politics of Affect. London: Polity.

McKay, Deirde. 2018. "Sent Home: Mapping the Absent Child into Migration Through Polymedia." Global Networks 18 (1): 133-50. https://doi.org/10.11 11/glob.12174.

Merriam, Sharan B., Juanita Johnson-Bailey, MingYeh Lee, Youngwha Kee, Gabo Ntseane, and Mazanah Muhamad. 2001. "Power and Positionality: Negotiating Insider/Outsider Status Within and Across Cultures." International Journal of Lifelong Education 20 (5): 405-16. https://doi.org/10.1080/026 01370120490.

Miguel, Cristina. 2016. “Visual Intimacy on Social Media: From Selfies to the Co-Construction of Intimacies Through Shared Pictures." Social Media + Society 2 (2): 205630511664170 . https://doi.org/10.11 $77 / 2056305116641705$.

Morley, David. 2003. "What's Home Got to Do with It? The Domestication of the Media and the Dislocation of Domesticity." European Journal of Cultural Studies 6 (4): 435-58. https://doi.org/10.1177/1367549403006 4001.

Nessi, Lorena, and Olga Guedes Bailey. 2014.

"Privileged Mexican Migrants in Europe: Distinctions and Cosmopolitanism on Social Networking Sites." Crossings: Journal of Migration \& Culture 5 (1): 121-37. https://doi.org/10.1386/cjmc.5.1.121 1.
Plummer, Ken. 2015. Cosmopolitan Sexualities: Hope and the Humanist Imagination. Cambridge, UK: Polity Press.

Pollock, David C., and Ruth E.Van Reken. 2009. Third Culture Kids. Growing Up Among Worlds. London: Nicholas Brealey Publishing.

Polson, Erika. 2016. Privileged Mobilities:

Professional Migration, Geo-Social Media, and a New Global Middle Class. New York, NY: Peter Lang Publishing.

Preser, Ruth. 2018. "What Therefore Discourse Has Joined Together: Sexuality, Performativity and Everyday Use of Public Spaces.” Social \& Cultural Geography, November, 1-18. https://doi.org/10.1080/ $\underline{14649365.2018 .1550805 .}$.

Reynolds, Tracey, and Elisabetta Zontini. 2013. “'Non-Normative' Family Lives? Mapping Migrant Youth's Family and Intimate Relationships across National Divides and Spatial Distance.” In Mapping Intimacies: Relations, Exchanges, Affects, edited by Tam Sanger and Yvette Taylor, 228-47. London, UK: Palgrave Macmillan UK. https://doi.org/10.1057/9781 13731342313.

Rodriguez, Jenny K., and Maranda Ridgway. 2018. "Contextualizing Privilege and Disadvantage: Lessons from Women Expatriates in the Middle East." Organization 26 (3): 391-409. https://doi.org/10.117 7/1350508418812580.

Sadowski, Helga. 2016. Digital Intimacies: Doing Digital Media Differently. Department of Thematic Studies: Linköping University.

Scheer, Monique. 2012. "Are Emotions a Kind of Practice (and Is That What Makes Them Have a History?) A Bourdieuian Approach to Understanding Emotion.” History and Theory 51 (2): 193-220. http s://doi.org/10.1111/i.1468-2303.2012.00621.x.

Sculz, Lukasz. 2020. "Queer Migrants and Digital Culture.” In The Sage Handbook of Media and Migration, edited by Smets Kevin, Koen Leurs, Myria Georgiou, Saskia Witteborn, and Radhika Gajjala, 220-32. London, UK: Sage.

Serafinelli, Elisa. 2018. "New Approaches to Digital Photography and Online Photosharing.” In Digital Life on Instagram (Digital Activism and Society: Politics, Economy and Culture In Network Communication), edited by Elisa Serafinelli, 1-45. Bingley, UK: Emerald Publishing Limited. https://do i.org/10.1108/978-1-78756-495-420181001.

Sheller, Mimi. 2018. Mobility Justice: The Politics of Movement in an Age of Extremes. London, UK: Verso. 
Sundén, Jenny. 2018. “Queer Disconnections: Affect, Break, and Delay in Digital Connectivity.”

Transformations 31: 63-78.

Taipale, Sakari. 2019. Intergenerational Connections in Digital Families. Switzerland: Springer.

The Dutch Organization for Internationalisation of Education. 2019. "Incoming Degree Student Mobility in Dutch Higher Education.” https://www.nuffic.nl/e $\mathrm{n}$ /publications/incoming-degree-student-mobility-du tch-higher-education-2018-2019/.

Tsagarousianou, Roza. 2020. “Diaspora as a Frame: How the Notion Has Reshaped Migration Studies.” In The Sage Handbook of Media and Migration, 9-16. London, UK: SAGE Publications Ltd. https://doi.org/1 0.4135/9781526476982.n4.

Twigt, Mirjam A. 2018. “The Mediation of Hope: Digital Technologies and Affective Affordances Within Iraqi Refugee Households in Jordan." Social Media + Society. https://doi-org.proxy.library.uu.nl/d oi/10.1177/1350508418812580.

Valentine, Gill. 2006. "Globalizing Intimacy: The Role of Information and Communication Technologies in Maintaining and Creating Relationships.” Women's Studies Quarterly 34 (1/2): 365-93.

-- - 2008. "The Ties That Bind: Towards Geographies of Intimacy.” Geography Compass 2 (6): 2097-2110. https://doi.org/10.1111/i.1749-8198.200 8.00158.x. van Meeteren, Masja. 2014. Irregular Migrants in Belgium and the Netherlands: Aspirations and Incorporation. Amsterdam: Amsterdam University Press. https://doi.org/10.1515/9789048523085.

Vasileiou, Konstantina, Julie Barnett, Susan Thorpe, and Terry Young. 2018. "Characterising and Justifying Sample Size Sufficiency in Interview-Based Studies: Systematic Analysis of Qualitative Health Research over a 15-Year Period.” BMC Medical Research Methodology 18 (1). https://doi.org/10.1186/s12874-0 18-0594-7.

Walsh, Katie. 2018. Transnational Geographies of the Heart. NJ: Wiley Blackwell. https://doi.org/10.1002/97 $\underline{81119050414}$.

Wekker, Gloria. 2016. White Innocence. Paradoxes of Colonialism and Race. Durham, NC: Duke University Press. https://doi.org/10.1215/9780822374565.

Wise, Amanda, and Selvaraj Velayutham. 2017. "Transnational Affect and Emotion in Migration Research.” International Journal of Sociology 47 (2): 116-30. https://doi.org/10.1080/00207659.2017.13004 68.

Witteborn, Saskia. 2018. “The Digital Force in Forced Migration: Imagined Affordances and Gendered Practices.” Popular Communication 16 (1): 21-31. htt ps://doi.org/10.1080/15405702.2017.1412442.

Yu, Sherry. 2019. "Beyond the Third Space: New Communictive Spaces in the Making on YouTube.” In The Sage Handbook of Media and Migration, edited by Smets Kevin, Koen Leurs, Myria Georgiou, Saskia Witteborn, and Radhika Gajjala, 526-36. London, UK: Sage. 